\title{
CORRIGENDUM
}

\section{Weight loss and long-term follow-up of severely obese individuals treated with an intense behavioral program}

\author{
JW Anderson, L Grant, L Gotthelf and LTP Stifler \\ International Journal of Obesity (2007) 31, 565. doi:10.1038/sj.ijo.0803541
}

Correction to: International Journal of Obesity (2007) 31, 488-493. doi:10.1038/sj.ijo.0803423

Since the publication of the above paper the authors have noticed an error in Table 1 . The asterisk should appear next to 26-week weight loss. The correct table is shown below:

The authors would like to apologise for the errors.

Table 1 Baseline data, weight loss and follow-up weights for different groups. Follow-up data represents the last clinic weight available

\begin{tabular}{|c|c|c|c|c|c|c|c|c|c|}
\hline & \multicolumn{3}{|c|}{ Study group } & \multicolumn{3}{|c|}{ Completers } & \multicolumn{3}{|c|}{ 100\# group } \\
\hline & Women & Men & All & Women & Men & All & Women & Men & All \\
\hline \multicolumn{10}{|l|}{ Group } \\
\hline Number & 998 & 533 & 1531 & 689 & 411 & 1100 & 121 & 147 & 268 \\
\hline Age (years) & 43 & 45 & 44 & 44 & 46 & 44 & 43 & 44 & 43 \\
\hline s.d. & 11.3 & 11.2 & 11.3 & 11.5 & 11.0 & 11.3 & 10.9 & 10.1 & 10.5 \\
\hline Initial weight (kg) & 128.2 & 158.6 & 138.8 & 129.0 & 157.9 & 139.8 & 139.9 & 173.7 & 158.4 \\
\hline s.d. & 21.4 & 29.7 & 28.5 & 21.1 & 29.3 & 28.2 & 25.8 & 33.5 & 34.6 \\
\hline Initial BMI $\left(\mathrm{kg} / \mathrm{m}^{2}\right)$ & 47.6 & 49.5 & 48.3 & 48.0 & 49.4 & 48.5 & 51.3 & 53.9 & 52.7 \\
\hline s.d. & 6.9 & 8.6 & 7.6 & 7.0 & 8.8 & 7.7 & 8.8 & 10.3 & 9.7 \\
\hline \multicolumn{10}{|l|}{ Weight loss phase } \\
\hline 12-week weight loss (kg) & $14.5^{\star}$ & $22.5^{\star}$ & $17.3^{*}$ & 18.2 & 27.0 & 21.2 & 23.9 & 33.9 & 29.3 \\
\hline s.e. & 0.3 & 0.5 & 0.3 & 0.3 & 0.6 & 0.3 & 0.4 & 0.7 & 0.5 \\
\hline 26-week weight loss $(\mathrm{kg})^{*}$ & 19.4 & 29.1 & 22.8 & 25.8 & 37.0 & 29.9 & 41.7 & 52.5 & 47.6 \\
\hline s.e. & 0.4 & 0.8 & 0.4 & 0.5 & 0.8 & 0.5 & 0.7 & 1.1 & 0.7 \\
\hline Total weight loss (kg) & 23.9 & 36.0 & 28.1 & 30.8 & 42.6 & 35.2 & 58.2 & 65.7 & 62.3 \\
\hline s.e. & 0.6 & 1.0 & 0.5 & 0.6 & 1.1 & 0.6 & 1.2 & 1.5 & 1.0 \\
\hline Total weight loss of initial weight (\%) & 18.5 & 22.5 & 19.9 & 23.9 & 26.7 & 24.9 & 41.5 & 37.5 & 39.8 \\
\hline s.e. & 0.00 & 0.01 & 0.00 & 0.00 & 0.01 & 0.01 & 0.01 & 0.01 & 0.01 \\
\hline Treatment, weeks & 28.8 & 32.6 & 30.1 & 38.1 & 39.0 & 38.5 & 64.5 & 50.8 & 57.0 \\
\hline s.e. & 1.4 & 1.9 & 1.1 & 1.8 & 2.3 & 1.4 & 5.8 & 4.2 & 3.5 \\
\hline \multicolumn{10}{|l|}{ Follow-up } \\
\hline Number available & 697 & 406 & 1103 & 589 & 358 & 947 & 117 & 134 & 251 \\
\hline$\%$ available & 69.8 & 76.2 & 72.0 & 85.5 & 87.1 & 86.1 & 96.7 & 91.2 & 93.7 \\
\hline Weight maintained $(\mathrm{kg})$ & 17.5 & 25.9 & 20.6 & 19.4 & 28.1 & 22.7 & 36.6 & 44.8 & 41.0 \\
\hline s.e. & 0.6 & 1.1 & 0.6 & 0.7 & 1.2 & 0.6 & 1.8 & 2.1 & 1.4 \\
\hline$\%$ Weight maintained (\%) & 59.7 & 63.1 & 61.0 & 57.0 & 62.2 & 59.0 & 62.5 & 67.5 & 65.1 \\
\hline s.e. & 0.02 & 0.02 & 0.02 & 0.02 & 0.02 & 0.02 & 0.03 & 0.02 & 0.02 \\
\hline Duration follow-up, weeks & 59.3 & 72.0 & 64.0 & 67.9 & 79.0 & 72.1 & 92.3 & 96.8 & 94.7 \\
\hline s.e. & 3.2 & 5.0 & 2.7 & 3.6 & 5.5 & 3.1 & 8.8 & 9.9 & 6.7 \\
\hline
\end{tabular}

Abbreviations: BMI, body mass index; s.d., standard deviation; s.e., standard error. *Last observation carried forward. 